Supporting Information

\title{
Self-Epitaxial Hetero-Nanolayers and Surface Atom Reconstruction in Electrocatalytic Nickel Phosphides
}

Xian-Kui Wei, ${ }^{*},{ }^{\dagger}$ Dehua Xiong, ${ }^{\ddagger}{ }^{\S}$ Lifeng Liu, ${ }^{\ddagger}$ and Rafal E. Dunin-Borkowski ${ }^{\dagger}$

${ }^{\dagger}$ Ernst Ruska-Centre for Microscopy and Spectroscopy with Electrons, Forschungszentrum Jülich GmbH, Jülich 52428, Germany

International Iberian Nanotechnology Laboratory (INL), Braga 4715-330, Portugal

${ }^{\S}$ State Key Laboratory of Silicate Materials for Architectures, Wuhan University of Technology, Wuhan 430070, China

*Correspondence author E-mail: x.wei@fz-juelich.de (X.K.W.) 

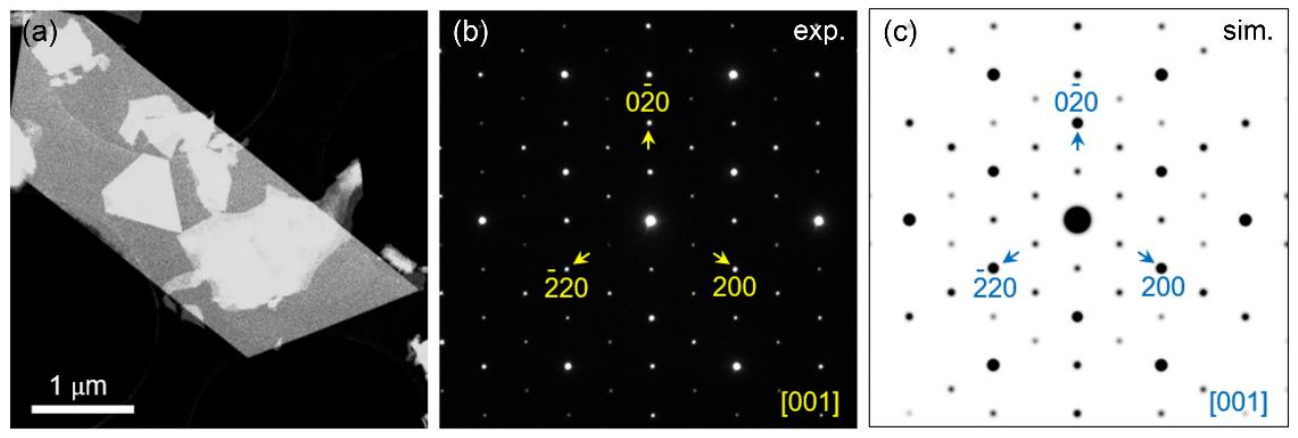

Figure S1. (a) Representative HAADF-STEM image of $\mathrm{Ni}_{5} \mathrm{P}_{4}$ nanosheets with preferential [001] orientation (one or two out of 20). (b,c) Selected area electron diffraction of $\mathrm{Ni}_{5} \mathrm{P}_{4}$ recorded along the [001] direction and the simulated one, respectively. Apart from the $\langle 2 \overline{4} 0\rangle^{*}$ diffraction spots, the $\langle 100\rangle^{*}$ diffraction spots show dramatic difference in intensity distribution in the reciprocal space. Being consistent with the high-resolution TEM and STEM results, the difference from the simulated electron-diffraction pattern also indicate clear features of surface atom reconstruction on the $\mathrm{Ni}_{5} \mathrm{P}_{4}$ nanosheets. 

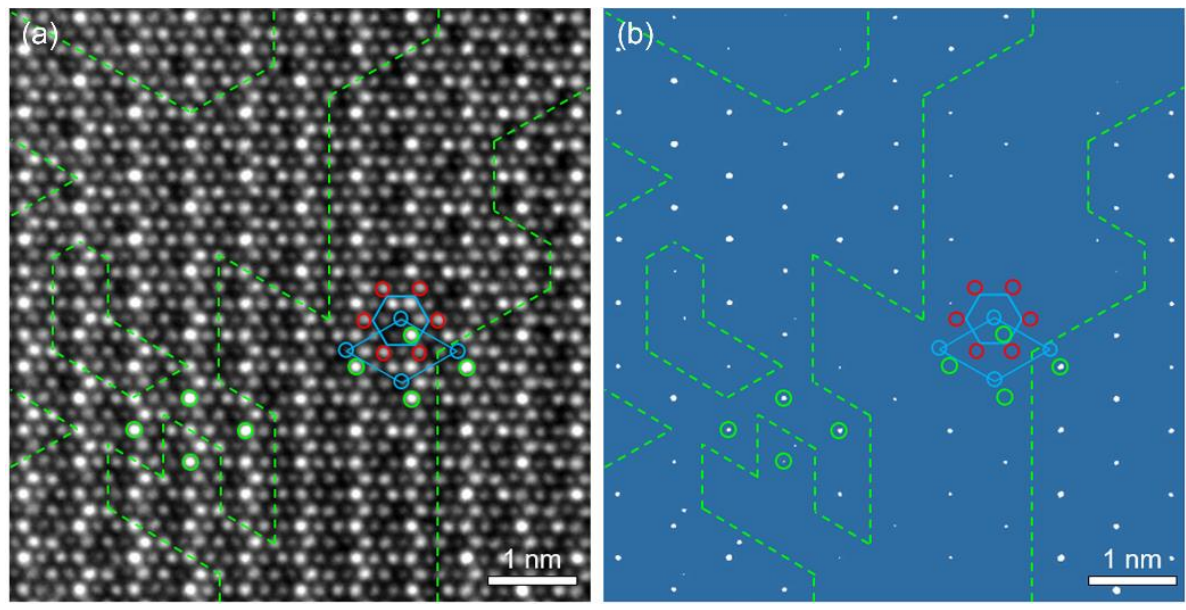

Figure S2. (a) A large-area view of the atomic-resolution TEM image presented in Figure 2c. It should be noted that the image intensity is normalized by a reference image recorded from a vacuum region under the same conditions during the experiments. (b) A filtered image of (a) via a certain intensity range $\left(I_{\max }-1.05 \sim I_{\max }\right)$ with respect to the maximum image intensity $\left(I_{\max }=\right.$ 3.46). From the $5 \pi / 3$-point columns (green circles), we can clearly see different intensity distribution over this local image area. This clearly reveals presence of atomic steps on surfaces of the $\mathrm{Ni}_{5} \mathrm{P}_{4}$ nanosheets. 


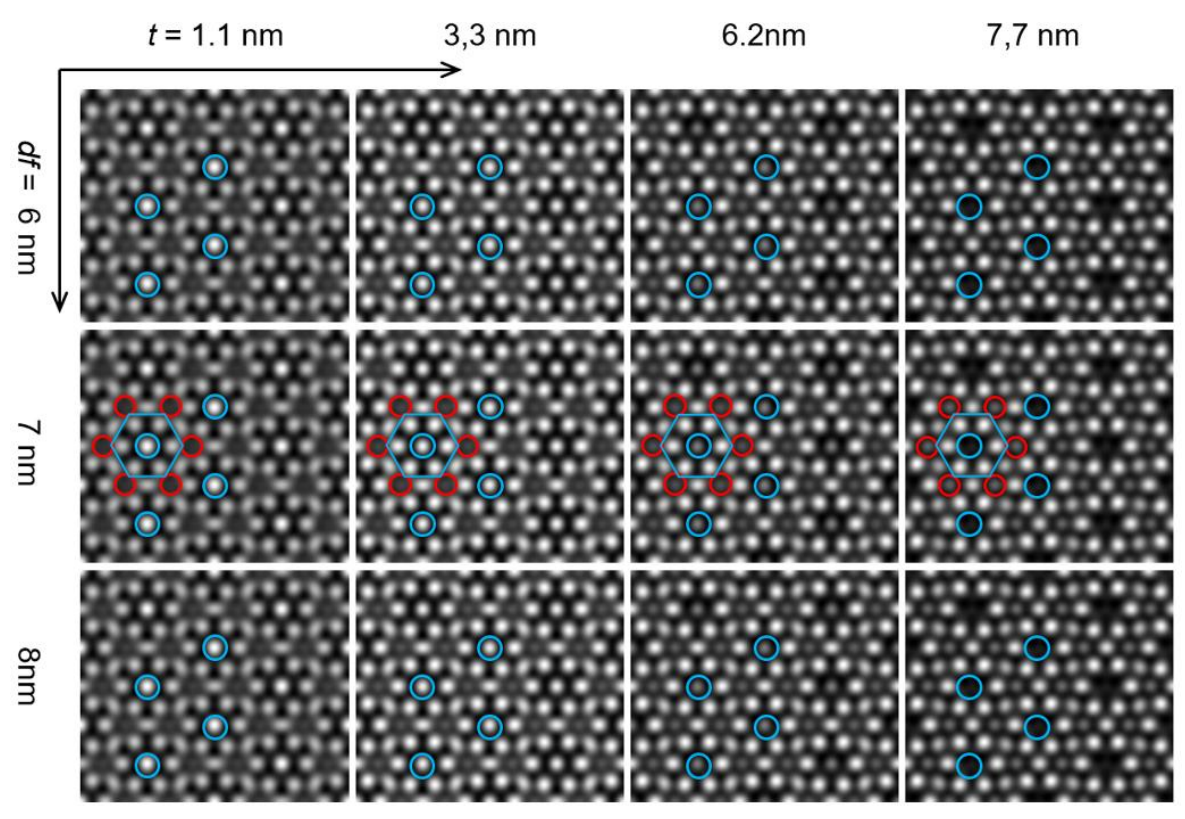

Figure S3. Simulated TEM image of $\mathrm{Ni}_{5} \mathrm{P}_{4}$ along the [001] direction. Positions of the CNP and pure $\mathrm{P}$ atom columns are marked by green and red circles. With increasing of the specimen thickness, we can clearly see monotonic decreasing of intensity for the CNP columns. This feature is unchanged in the illustrated defocus range $(d f=6,7$ and $8 \mathrm{~nm})$. Apart from this, we see that the intensities of six-fold-symmetric NCNP columns keep equivalent under each of the thickness and defocus condition. With increasing of the specimen thickness, we also see monotonic increase of column intensity for the six-fold-symmetric pure $\mathrm{P}$ atoms along this direction. 

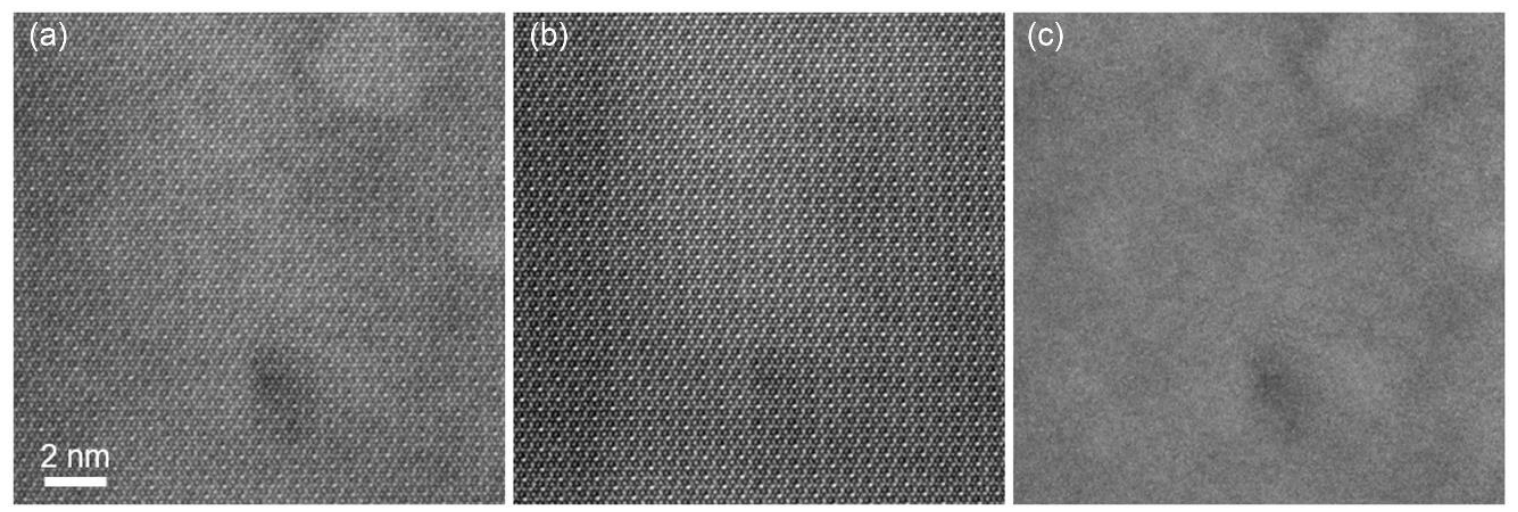

Figure S4. (a) Original atomic-resolution HAADF-STEM image of [001]-oriented $\mathrm{Ni}_{5} \mathrm{P}_{4}$ nanosheet. (b) Filtered HAADF-STEM image with removal of signal from the amorphous by a Wiener or average background subtraction. (c) Difference between the original and filtered image. From this image area, we clearly see a homogeneous distribution of reconstructed $\mathrm{Ni}$ atoms on the phosphide surface. After removal of the signal from the amorphous, several smaller regions of interest in (b) are selected and averaged to further improve signal-to-noise ratio. The averaged image is presented in Figure 2a. 


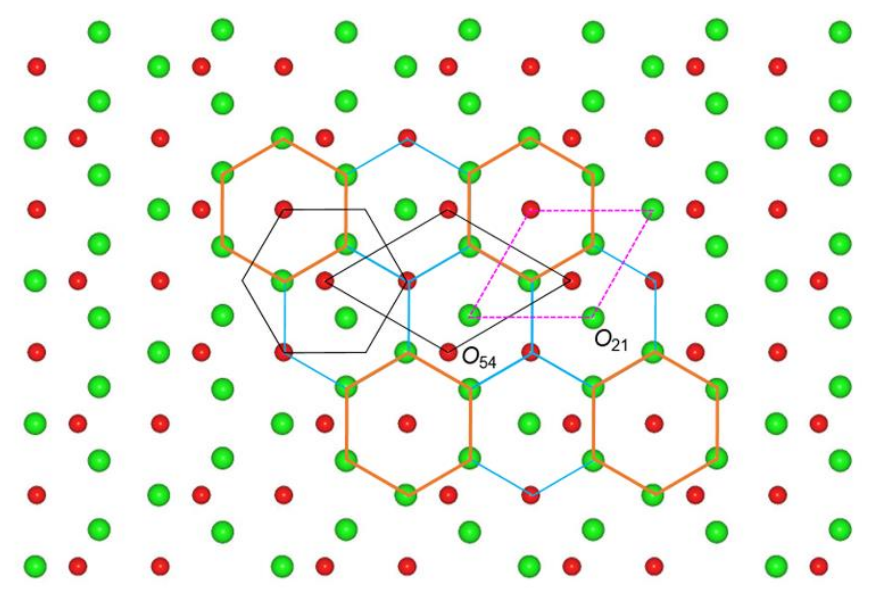

Figure S5. Structural model of $\mathrm{Ni}_{3} \mathrm{P}_{2}$ sublayer of $\mathrm{Ni}_{5} \mathrm{P}_{4}$ viewed along [001] direction. The black parallelogram and largest hexagon denote the PUC and ETUC of $\mathrm{Ni}_{5} \mathrm{P}_{4}$. The pink dashed parallelogram and smaller hexagons (orange and blue) denote the PUC and ETUC of $\mathrm{Ni}_{2} \mathrm{P}$. Repartition of the $\mathrm{Ni}_{3} \mathrm{P}_{2}$ sublayer by the ETUCs of $\mathrm{Ni}_{2} \mathrm{P}$ also shows two kinds of ETUCs 21 , the orange hexagons with a composition of $\mathrm{Ni}_{2} \mathrm{P}_{1}$ and the linking blue hexagons with a composition of $\mathrm{Ni}_{7 / 3} \mathrm{P}_{5 / 3}$. From the atomic occupation in this sublayer, one can see that none of the ETUCs ${ }_{21}$ have similarity to any sublayer of $\mathrm{Ni}_{2} \mathrm{P}$. Compared with the $\mathrm{Ni}_{3} \mathrm{P}_{3}$ and $\mathrm{Ni}_{4} \mathrm{P}_{3}$ terminations, this suggests that the $\mathrm{Ni}_{3} \mathrm{P}_{2}$ is not a favorable termination for epitaxial growth of $\mathrm{Ni}_{2} \mathrm{P}$ on top of $\mathrm{Ni}_{5} \mathrm{P}_{4}$. 

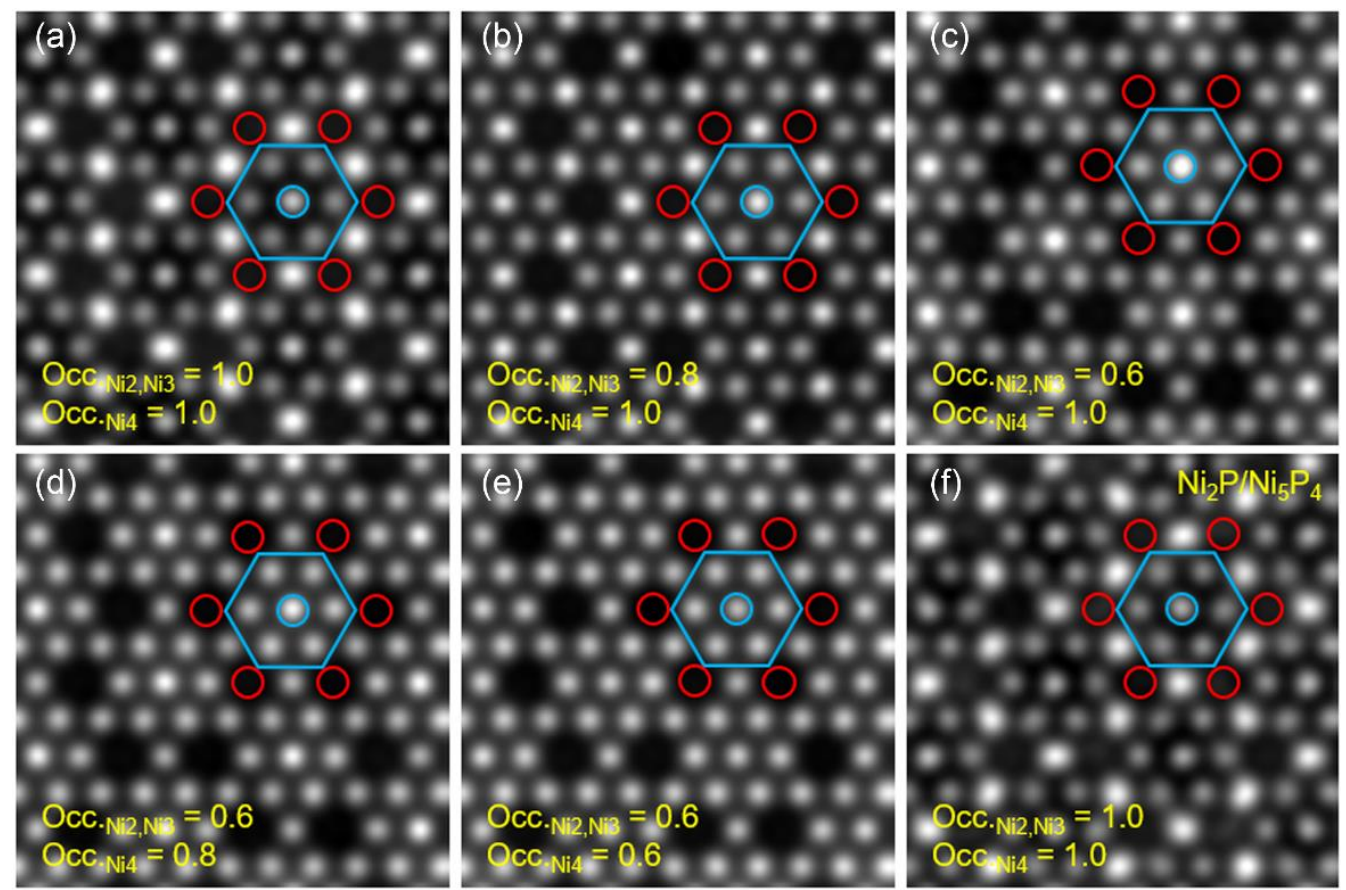

Figure S6. Simulated HAADF images of $\mathrm{Ni}_{5} \mathrm{P}_{4}$ with different Ni occupation and overlapping of $\mathrm{Ni}_{2} \mathrm{P}$ on top along [001] direction. (a-c) Simulated HAADF images with occupation (Occ.) of Ni2and Ni3-site atoms at $1.0(\mathrm{a}), 0.8(\mathrm{~b})$ and $0.6(\mathrm{c})$ with Occ. $\mathrm{Ni4}=1.0 .(\mathrm{d}, \mathrm{e})$ Image simulation with occupation (Occ.) of Ni2- and Ni3-site atoms setting as Occ. $=0.6$ while Occ. Ni4 $=0.8$ and 0.6 , respectively. (f) Simulated image of $\mathrm{Ni}_{2} \mathrm{P}(2.2 \mathrm{~nm}) / \mathrm{Ni}_{4} \mathrm{P}_{3}-\mathrm{Ni}_{5} \mathrm{P}_{4}(38.5 \mathrm{~nm})$ along [001] direction with full occupation of all atoms. 


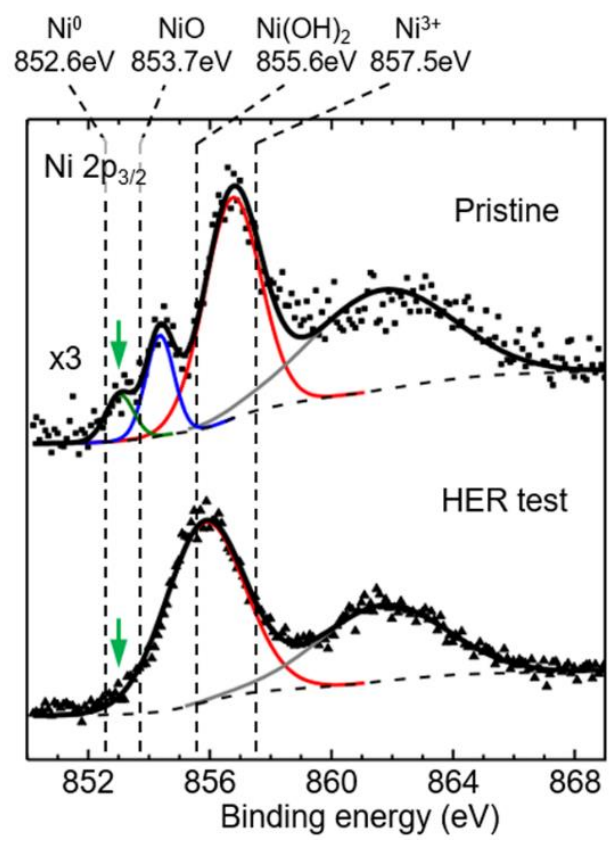

Figure S7. XPS spectra of Ni $2 p_{3 / 2}$ for the $\mathrm{Ni}_{\mathrm{x}} \mathrm{P}_{\mathrm{y}}$ nanosheets before and after the HER test. The peaks are fitted based on simple models. For ease of comparison, typical binding energies about Ni-containing species are marked out. The $\mathrm{Ni}$ valence (green arrows) in the range of $0 \sim 1$ suggests reconstruction of $\mathrm{Ni}$ atoms with $\mathrm{P}$ and other relevant atoms on the phosphide surfaces. 


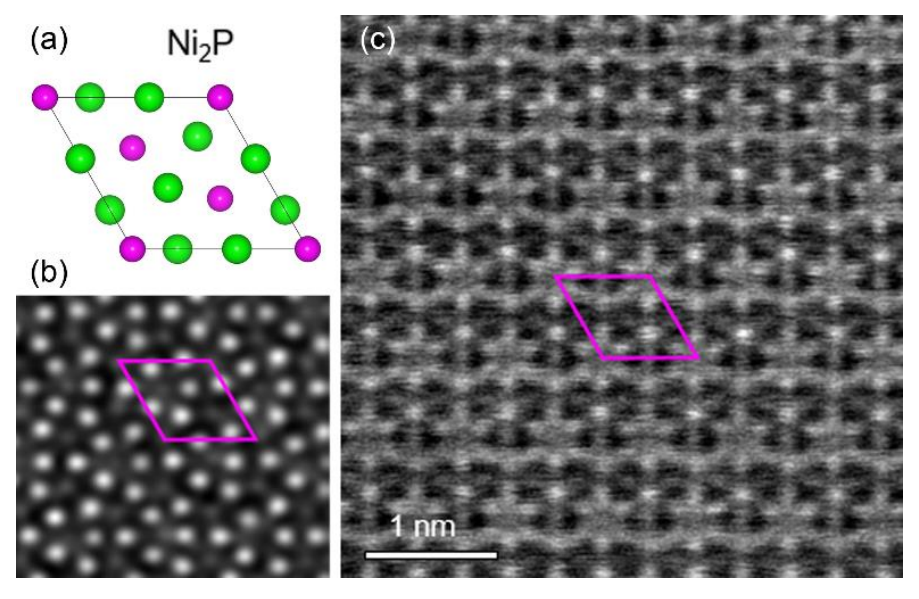

Figure S8. (a,b) Crystal structure and simulated HAADF-STEM image of $\mathrm{Ni}_{2} \mathrm{P}$ along the [001] direction. (c) Atomic-resolution $\mathrm{HAADF}$ image of $\mathrm{Ni}_{2} \mathrm{P}$ collected along the [001] direction. Corresponding to the enriched $\mathrm{Ni}$ detected by EDX, difference of the atom-column features between experimental and simulated images also evidences reconstruction of $\mathrm{Ni}$ atoms on surfaces of the $\mathrm{Ni}_{2} \mathrm{P}$ phase. This further supports reconstruction of $\mathrm{NiP}_{\mathrm{x}}(0<\mathrm{x}<0.5)$ on top of $\mathrm{Ni}_{2} \mathrm{P}$-covered $\mathrm{Ni}_{5} \mathrm{P}_{4}$ phase. 
Table S1. Atomic position, Debye-Waller factor and occupation of atoms in $\mathrm{Ni}_{5} \mathrm{P}_{4}$ and $\mathrm{Ni}_{2} \mathrm{P}$ used for quantitative image simulation.

\begin{tabular}{|c|c|c|c|c|c|c|}
\hline Phase & Atom & $\mathrm{x}$ & $\mathrm{y}$ & $\mathrm{z}$ & $\mathrm{B} /\left[\AA^{2}\right]$ & Occ. \\
\hline \multirow[t]{2}{*}{$\mathrm{Ni}_{5} \mathrm{P}_{4}$} & Ni1 & 0.1778 & 0.8222 & 0.2365 & 0.44 & 1.0 \\
\hline & $\mathrm{Ni} 2$ & 0.5057 & 0.4943 & 0.0872 & 0.44 & 0.6 \\
\hline Lattice parameter & $\mathrm{Ni} 3$ & 0.5118 & 0.4882 & 0.3775 & 0.44 & 0.6 \\
\hline$a=0.67894 \mathrm{~nm}$ & $\mathrm{Ni} 4$ & 0.0000 & 0.0000 & 0.1989 & 0.42 & 0.8 \\
\hline \multirow[t]{4}{*}{$c=1.0989 \mathrm{~nm}$} & P1 & 0.1567 & 0.8433 & 0.4406 & 0.43 & 1.0 \\
\hline & $\mathrm{P} 2$ & 0.8391 & 0.1609 & 0.2306 & 0.47 & 1.0 \\
\hline & P3 & 0.3333 & 0.6667 & 0.0556 & 0.36 & 1.0 \\
\hline & $\mathrm{P} 4$ & 0.0000 & 0.0000 & 0.0000 & 0.39 & 1.0 \\
\hline $\mathrm{Ni}_{2} \mathrm{P}$ & Ni1 & 0.2575 & 0.0000 & 0.5000 & 0.45 & 1.0 \\
\hline Lattice parameter & $\mathrm{Ni} 2$ & 0.5957 & 0.0000 & 0.0000 & 0.45 & 1.0 \\
\hline$a=0.5880 \mathrm{~nm}$ & $\mathrm{P} 1$ & 0.3333 & 0.6667 & 0.5000 & 0.50 & 1.0 \\
\hline$c=0.3382 \mathrm{~nm}$ & $\mathrm{P} 2$ & 0.0000 & 0.0000 & 0.0000 & 0.50 & 1.0 \\
\hline
\end{tabular}

